\title{
GNSS Technology's Contribution to Topography: Evaluative Study of Gaps between Methods Topographies
}

\author{
Cheikh Ahmed Tidiane Ly ${ }^{1}$, Joseph Mbagnick Louis Diene ${ }^{1}$, Diogoye Diouf ${ }^{1}$, Alassane Ba ${ }^{2}$ \\ ${ }^{1}$ Unité de Formation et de Recherches-Sciences de l'Ingénieur, Université Iba Der THIAM of Thiès, Thiès, Sénégal \\ ${ }^{2}$ Ecole Polytechnique de Thiès, Thiès, Sénégal \\ Email: cahtly@gmail.com
}

How to cite this paper: Ly, C.A.T., Diene, J.M.L., Diouf, D. and Ba, A. (2021) GNSS Technology's Contribution to Topography: Evaluative Study of Gaps between Methods Topographies. Journal of Geographic Information System, 13, 340-352.

https://doi.org/10.4236/igis.2021.133019

Received: March 12, 2021

Accepted: May 31, 2021

Published: June 3, 2021

Copyright $\odot 2021$ by author(s) and Scientific Research Publishing Inc. This work is licensed under the Creative Commons Attribution International License (CC BY 4.0).

http://creativecommons.org/licenses/by/4.0/

\begin{abstract}
New information and communication technologies have led to the emergence of new techniques in our daily lives. Indeed, in topography, a lightning development of new techniques and new devices has been noticed. This development has given rise to a multitude of choices of devices and various classes of precision. This implies that the decision-makers have to study the adequate equipment and the appropriate technique according to the topographic task to be realized. The objective is not to compare GNSS and topographic techniques, but to point out the contribution of the Global Navigation Satelite System (GNSS) techniques of topographic work. Thus, a theoretical study with a critical eye on the scientific principle of calculating the third topographic dimension followed by a leveling campaign, Real Time Kinematic (RTK) surveys will be used in order to be able to compare and interpret the result from these campaigns. The study of the difference resulting from the practical campaigns will allow us to identify the contribution of GNSS technology.
\end{abstract}

\section{Keywords}

Topography, GNSS, Technic, Accuracy, Contribution

\section{Introduction}

The execution of topographic work usually requires the prior existence of geodetic benchmarks to be used for referencing the data from the measurements. With the Spatial Positioning System, most reference points are now directly determined in 3D. 
In order to meet this requirement, a durable network of points is needed to determine the planimetric and altimetric positions of objects (or points) on the earth's surface. In Senegal, the 1953 General Levelling of West Africa (NGAO53) and the 2004 Reference Network of Senegal (RRS04) are the official height and planimetric reference systems. It should be noted that the determination of heights generally poses more problems for professionals in countries such as Senegal, where height benchmarks are not as accessible [1]. These benchmarks are often confronted with certain physical factors leading to deformations of the earth's crust and facto benchmarks.

In this work, the contribution of Global Navigation Satellite System (GNSS) technology to the estimation of the third dimension is highlighted. Thus, leveling campaigns and GPS surveys were carried out in order to identify the contribution of GNSS technology in topography. Following the direct leveling operations, Real Time Kinematic (RTK) and fast static surveys were carried out with the integration of the EGM2008 geoid model for the determination of heights from the determined heights and interpolated undulations. A comparison of these two types of measurements was used to assess the accuracy of EGM2008 in the study area.

\subsection{Geometric Leveling}

Direct leveling or geometric leveling is a topographic operation carried out with the aid of a level and a staff, which makes it possible to determine the difference in level (commonly known as geometric height difference) between two points from horizontal sights taken on a staff. The calculation of heights from this operation is based on the knowledge of the level differences and the initial height [2].

This operation is often used in topography to perform a height adjustment, which requires a vertical reference network.

Of course, the level difference between two points does not depend directly on the path followed, unlike measured differences in level ([3], p 40-p 41). So, is it possible to characterise this variable as a state function? A state function is a physical variable whose variation depends only on the initial and final states and not on the path followed ([4], p 3).

The back and front readings vary with the path followed and the height of the station, whereas the difference in level along a chosen path depends on the back and front readings. Analysing the elevation potential, it becomes clear that it is not the elevation difference that is a constant but rather the potential difference ([3], p 41).

On the other hand, considering this element as such, it would be interesting to apply Schwartz's theorem on the total differential. The application of this formula on the level difference is given by equation number 1 below:

$$
\frac{\partial^{2} d n}{\partial \operatorname{Lar} \partial \operatorname{Lav}}=\frac{\partial}{\partial \operatorname{Lar}}\left[\frac{\partial d n}{\partial \operatorname{Lav}}\right]=1 \text { ? }
$$


Applying this formula actually gives a null value to the double differential: this shows that the gradient is not a state function. In a classical way, this difference in level remains a constant between two points. But in the case where one of the points would have undergone a movement then this difference in level becomes a variable function with the environment of measurement that we could estimate. Could a monitoring study within the framework of auscultation estimate in a particular way this temporal variation?

For a path between two points, there is a link between the backward and forward readings. There is a real such that:

$$
l a r=l a v+\varepsilon
$$

$\varepsilon$ is such that the height difference between these two points remains constant. Therefore, $\varepsilon$ does not vary and remains constant.

Thus, the difference in level can be expressed as such:

$$
\begin{gathered}
d n=l a v+\varepsilon-l a v=\varepsilon=\text { cste } \\
\frac{\partial \partial d n}{\partial \operatorname{Lar} \partial \operatorname{Lav}}=0
\end{gathered}
$$

The contradiction between (1) and (4) is an actual limit of direct leveling.

\subsection{GNSS Leveling}

Satellite positioning systems have made a great contribution to the accurate determination of points on the earth's surface. However, the determination of the altimeter component was one of the limitations of this system, as it could only measure the height relative to the associated ellipsoid. This did not correspond to the physical quantity (altitude) that users were interested in. It was not until the development of geoid models that could be integrated into GNSS receivers or calculation software to obtain heights from these measurements and the undulation provided by the model. Several models have been implemented such as EGM 96 and EGM08.

The functions used to determine the ripples are calculated according to harmonic models [5] [6] [7] [8].

The ripples associated with the EGM08 model are calculated on each of the grid nodes with harmonic functions expandable to degrees n. ([3], p 44). The following ripple formula can be used:

$$
N=\frac{T}{\gamma}=\frac{G M}{\gamma} \sum_{n=2}^{\infty} \frac{a_{e}^{n}}{r^{n+1}} \sum_{m=0}^{n} P_{n, m}(\sin \varphi)\left(C_{n, m}^{*} \cos m \lambda+S_{n, m}^{*} \sin m \lambda\right)
$$

\section{Methodology}

The objective of this paper is to highlight the contribution of GNSS in some conventional surveying work.

The approach adopted is to establish a base polygon by conventional surveying methods. The different points of the polygon were also observed by GNSS 
methods (RTK and fast static).

The second part consists of studying the altimetric coupling of GNSS and the conventional method. Knowing the order of magnitude of the differences, a study is conducted to reconcile the two methods.

\section{Experimentation and Results}

\subsection{Study Site}

The study area is located in Thies, more precisely in the HLM district of Mbour, just to the right of the road leading to Mbour at the level of the Lat. Dior stadium. The geographical coordinates of the study area vary in longitude between $-16.945^{\circ}$ and $-16.950^{\circ}$ and in latitude between $14.774^{\circ}$ and $14.776^{\circ}$.

The study area is illustrated in Figure 1 and Figure 2.

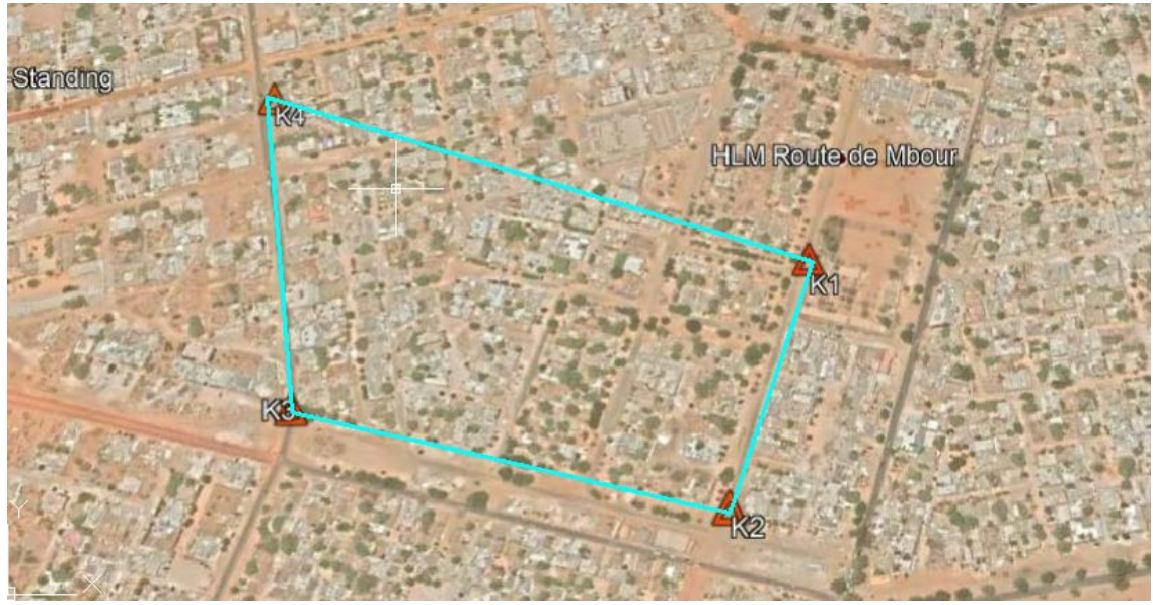

Figure 1. Map view of the study area through (Google Earth).
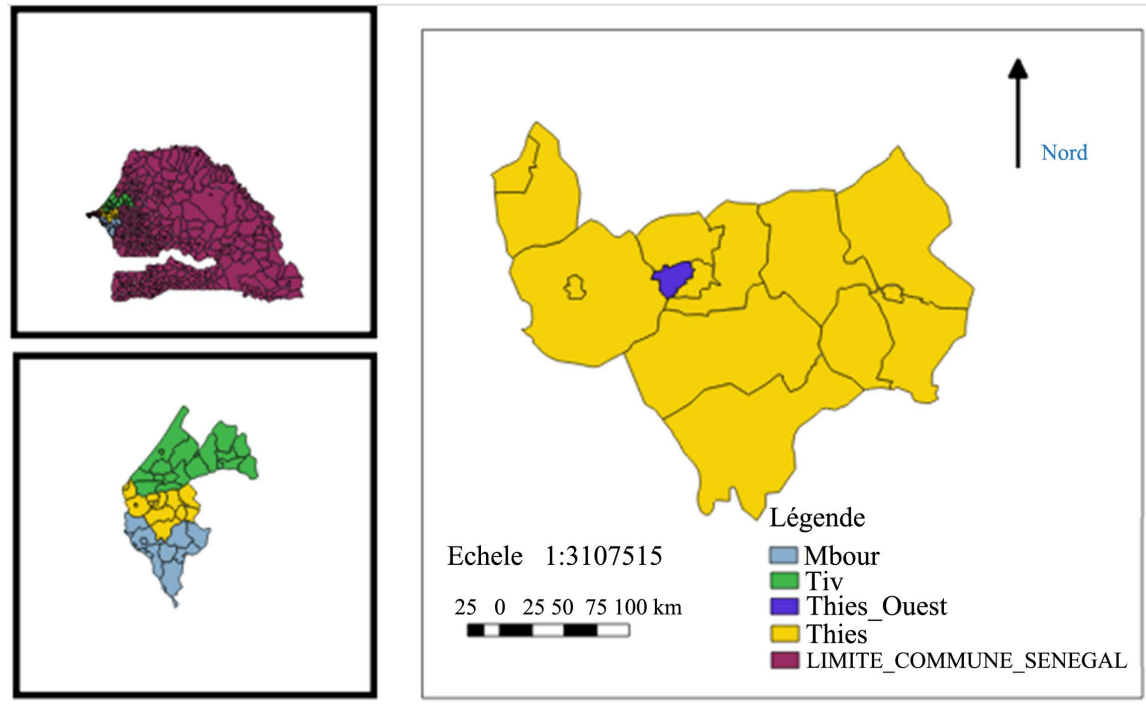

Projection: UTM WGS 84

Source: ANSD 2019

Auteurs: Cheikh ATLY \& Joseph M LDIENE

Figure 2. Map of the Thies region and location of the study area. 


\subsection{Development of the GNSS Framework}

GNSS observation in fast static mode is becoming increasingly easy ([9], p 462). In addition to the accuracy, these modes require a limited number of operators (one to two people) and can be performed with limited resources. The use of the fast static mode requires more time in some measurement jobs where the number of points to be measured is high or with relatively large baselines. Indeed, resolving ambiguities on each new point requires a considerable amount of time to observe each point and cannot be used for economic reasons on applications such as longitudinal profile measurement or DTM measurement. The use of static and kinematic mode provides speed and accuracy in the realisation of GNSS base points [10]. It is also possible to produce the base map in altimetry as well as in planimetry, both during the day and at night, if sufficient satellites with good geometry are available. The processing of the observations is done with GNSS calculation software and the execution of the calculations is done in a few minutes. However, GNSS methods have some disadvantages: dependence on the measurement environment, dependence on external structures (the constellation), accuracy depending on the length of the baseline, working only externally, etc. For this step, four points were observed by the fast static method and the post-processing was done with the Leica geo office software. The observation time was fifteen minutes on each point and this choice was strongly dependent on the length of the baselines.

Table 1 and Table 2 list the variation of coordinates in meters and degrees respectively. Also, the results of these tables are illustrated in Figure 3 and Figure 4 respectively.

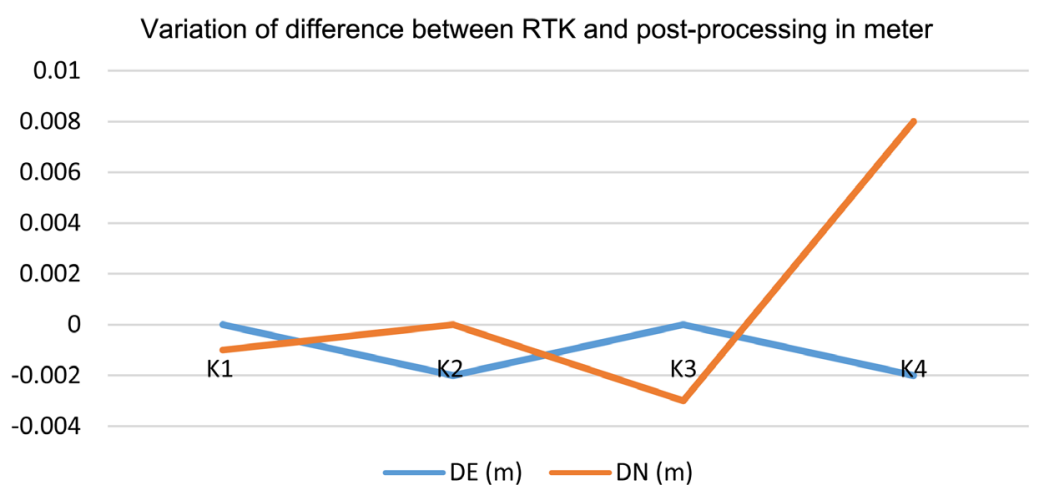

Figure 3. Variation curve of the plane coordinate difference in meters.

Table 1. Difference in plane coordinates between the fast static method and RTK.

\begin{tabular}{ccc}
\hline Stations & $\Delta E(\mathrm{~m})$ & $\Delta N(\mathrm{~m})$ \\
\hline $\mathrm{K} 1$ & 0 & -0.001 \\
$\mathrm{~K} 2$ & -0.002 & 0 \\
$\mathrm{~K} 3$ & 0 & -0.003 \\
$\mathrm{~K} 4$ & -0.002 & 0.008 \\
\hline
\end{tabular}




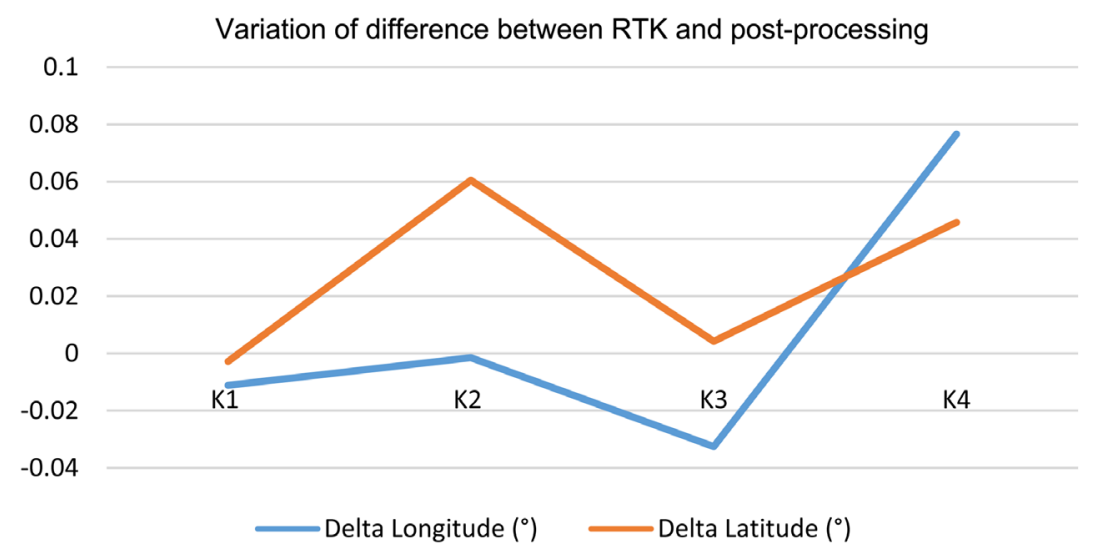

Figure 4. Variation curve of the difference in geographical coordinates.

Table 2. Difference in geographical coordinates between the fast static method and RTK.

\begin{tabular}{ccc}
\hline & $\Delta \varphi\left(^{\circ}\right)$ & $\Delta \lambda\left(^{\circ}\right)$ \\
\hline K1 & -0.01112 & -0.00280 \\
K2 & -0.00147 & 0.06053 \\
K3 & -0.03254 & 0.00424 \\
K4 & 0.07668 & 0.04583 \\
\hline
\end{tabular}

In this section, the graph shows that small (millimeter) deviations were obtained between the RTK and fast static solutions. These small differences in our case are mainly due to the short baselines obtained. These could quickly reach the centimeter (or even a few centimeters) if the baselines exceeded ten kilometers. This could make fast static positioning acceptable in contrast to RTK. It would therefore be better to proceed with the central pivot method, which would consist of creating and calculating a first station centred in the study area by static or fast static methods (depending on the baseline). This station would then serve as a pivot for the different observations in fast static mode or in RTK (if the baselines are weak) as in our case. This would guarantee a certain accuracy and speed.

\subsection{Elaboration of the Polygonation with a Total Station}

For this phase, a framed polygon between points $\mathrm{K} 3$ and $\mathrm{K} 2$ was made. To do this, angle and distance measurements were made on each vertex of the polygon. The result is tabulated in Table 3.

The advantage of this method is that it has the particularity of being the possible technique for making a canvas when the conditions for using GNSS are not met, a possibility for working indoors as well as outdoors. It usually requires a team of three people, including a chief surveyor, an operator, a survey assistant and possibly a driver.

The disadvantage of this method is that it requires a lot of time for execution and precision depending on the length of the sides of the polygonal. Also, it is 
Table 3. Raw polygon results.

\begin{tabular}{|c|c|c|c|c|}
\hline Stations & Target Point & Distances & Angles & Gisement \\
\hline \multirow{3}{*}{ K3 } & $\mathrm{K} 2$ & \multirow{3}{*}{174.015} & \multirow{3}{*}{273.8444} & 323.822283 \\
\hline & & & & \\
\hline & S11 & & & 397.666683 \\
\hline \multirow[b]{2}{*}{ ST1 } & K3 & \multirow[b]{2}{*}{80.281} & \multirow[b]{2}{*}{300.5506} & 197.666683 \\
\hline & ST2 & & & 98.217283 \\
\hline \multirow{3}{*}{ ST2 } & ST1 & \multirow{3}{*}{155.479} & \multirow{3}{*}{296.6812} & 298.217283 \\
\hline & & & & \\
\hline & ST3 & & & 194.898483 \\
\hline \multirow[b]{2}{*}{ ST3 } & ST2 & \multirow[b]{2}{*}{48.564} & \multirow[b]{2}{*}{124.44167} & 394.898483 \\
\hline & ST4 & & & 119.340153 \\
\hline \multirow{3}{*}{ ST4 } & ST3 & \multirow{3}{*}{101.38} & \multirow{3}{*}{74.1056} & 319.340153 \\
\hline & & & & \\
\hline & 315 & & & $393.445 / 53$ \\
\hline \multirow{3}{*}{ ST5 } & ST4 & \multirow{3}{*}{93.297} & \multirow{3}{*}{313.3} & 193.445753 \\
\hline & & & & \\
\hline & ST6 & & & 106.745753 \\
\hline \multirow{3}{*}{ ST6 } & ST5 & \multirow{3}{*}{85.682} & \multirow{3}{*}{229.6805} & 306.745753 \\
\hline & & & & \\
\hline & ST7 & & & 136.426253 \\
\hline \multirow{3}{*}{ ST7 } & ST6 & \multirow{3}{*}{118.682} & \multirow{3}{*}{188.3749} & 236.426253 \\
\hline & & & & \\
\hline & ST8 & & & 124.801153 \\
\hline \multirow{3}{*}{ ST8 } & ST7 & \multirow{3}{*}{77.998} & \multirow{3}{*}{107.2648} & 324.801153 \\
\hline & & & & \\
\hline & $\mathrm{K} 1$ & & & 32.065953 \\
\hline \multirow{3}{*}{$\mathrm{K} 1$} & ST8 & \multirow{3}{*}{228.169} & \multirow{3}{*}{392.5553} & 232.065953 \\
\hline & & & & \\
\hline & K2 & & & 224.621253 \\
\hline
\end{tabular}

only carried out during the day, a restriction due to the total station. It also requires the knowledge of two or more landmarks. Also, it has a low dependency on the measurement environment, some interoperability problems (Prism Constant), independence from external structures. It is generally more easily influenced by certain sources of error.

After the field phase, the raw data has to be compensated when the closure is below the tolerance. This processing can be done with topometric software, by hand calculation or in Excel. This processing can take several tens of minutes compared to the GNSS method. Table 4 lists the validation of the polygonal.

The financial costs for the realization of this method are variable and depend on the number of staff and the execution time as well as on the expected accuracy.

Table 5 gives the results of the compensated polygonal.

\subsubsection{Results with Some Stations Measured with the RTK Method}

Three points were surveyed by RTK method. The result of this survey is listed in Table 6. 
Table 4. Polygonal validation.

$\begin{array}{cc}\begin{array}{c}\text { Angular closing (mgon) } \\ f_{a}=G_{\text {arrivedos }}-G_{\text {arrived }}\end{array} & -3.5825 \\ \text { Planimetric closure (cm) } & 7.18 \\ f_{p}=\sqrt{f_{x}^{2}+f_{Y}^{2}} & \\ \text { Compensation } & \\ C_{i}=\frac{-f_{a}}{\sum_{i=1}^{n} p_{i}} * p_{i} & \\ \text { Angular tolerance (mgon) } & \\ \sqrt{12.96+36(n+1)} & \\ \text { Planimetric tolerance } & \\ \sqrt{16+16 n+160 \sum_{i=1}^{n} L_{i}^{2}} & \end{array}$

Table 5. Compensated results of the polygon.

\begin{tabular}{ccc}
\hline STATIONS & $E(\mathrm{~m})$ & $N(\mathrm{~m})$ \\
\hline ST1 & $290,117.9530$ & $1,634,401.8200$ \\
ST2 & $290,198.2000$ & $1,634,404.0699$ \\
ST3 & $290,210.6420$ & $1,634,249.0952$ \\
ST4 & $290,256.9780$ & $1,634,234.5745$ \\
ST5 & $290,246.5590$ & $1,634,335.4269$ \\
ST6 & $290,339.3300$ & $1,634,325.5622$ \\
ST7 & $290,411.3600$ & $1,634,279.1717$ \\
ST8 & $290,521.1450$ & $1,634,234.0976$ \\
\hline
\end{tabular}

Table 6. RTK survey results.

\begin{tabular}{ccc}
\hline STATIONS & $E(\mathrm{~m})$ & $\boldsymbol{N}(\mathrm{m})$ \\
\hline ST2 & $290,198.184$ & $1,634,404.082$ \\
ST3 & $290,210.615$ & $1,634,249.054$ \\
ST6 & $290,339.273$ & $1,634,325.545$ \\
\hline
\end{tabular}

\subsubsection{RTK and Compensated Polygonal Comparison}

The comparison of coordinates between RTK and base polygon surveys is shown in Table 7.

Comparing the coordinates obtained by the fast static method and by the RTK method, it is noted that the differences between these two methods are millimetric in our practical case. In the logic of noting these differences in accuracy, a comparison of the coordinates obtained by RTK method and by classical polygonation method has been made. Table 7 shows a difference ranging from 1 to 5 $\mathrm{cm}$. 
Table 7. Differences between RTK and polygonal results.

\begin{tabular}{ccc}
\hline STATIONS & $\Delta E(\mathrm{~m})$ & $\Delta N(\mathrm{~m})$ \\
\hline ST2 & -0.016 & 0.0121 \\
ST3 & -0.027 & -0.0412 \\
ST6 & -0.057 & -0.0172 \\
\hline
\end{tabular}

In summary, the coordinates calculated and compensated by the polygonal method are close to the RTK coordinates by a few centimeters. Using the conventional method for this type of work requires a lot of set-up and tedious work. GPS saves time and reduces the cost of the work with less risk.

The polygonation method therefore requires more time and a team of more than three people. It gives a centimetric accuracy compared to the coordinates obtained by GNSS post-processing.

\subsection{Attachment of the Polygonal Points to the NGA053}

The method adopted for connecting the points of the polygon is direct leveling. This method has the following advantages: spontaneous reading of the difference in level, ease of implementation, speed of measurement and millimeter accuracy.

The disadvantages of this method are the limitation of the ranges due to the instrument used, the dependence on the measuring environment, a problem of visibility between two successive measuring points and numerous stations when the points are far apart.

This leveling operation will make it possible to find the altitude of the base points in the study area. It will allow comparison of the variations in undulations deduced by post-processing and by RTK.

A closed path is applied to point TH02. After completing this path, which contains point $\mathrm{K} 1$, another closed path is performed around $\mathrm{K} 1$ to find the altitude of the post-processed points.

Table 8 gives the elements for calculating the tolerance according to the type of canvas. Once the type of canvas is chosen, the dimension of point $\mathrm{K} 1$ is determined from POINT TH02. This path is shown in Table 9.

From point K1, the heights of the other points are found. This path is given in Table 10 and summarized in Table 11.

Table 11 summarizes the different heights of the points.

\subsubsection{Variation of Ripples in the Study Site}

According to [1], the ripple $\mathrm{N}$ is described as the difference between the ellipsoidal height and the orthometric height.

Table 12 summarizes the heights and ripples and Table 13 shows the variation of the ripple as a function of latitude and longitude.

The tables summarise the deviations of the geographical coordinates of points $\mathrm{K} 1, \mathrm{~K} 2, \mathrm{~K} 3$ and $\mathrm{K} 4$ and the variation of the undulations. These variations have been calculated with reference to the coordinates and waviness of point K1. 
Table 8. Result of the closed path around TH02.

\begin{tabular}{ccc}
\hline Tolerance in mm & $n \leq 16$ & $n>16$ \\
\hline ordinary & $4 * \sqrt{36 * L+L^{2}}$ & $\sqrt{36 * N+N^{2} / 16}$ \\
accuracy & $4 * \sqrt{9 * L+L^{2}}$ & $\sqrt{9 * N+N^{2} / 16}$ \\
High accuracy & $8 * \sqrt{L}$ & $2 * \sqrt{N}$ \\
\hline
\end{tabular}

With $n=N / L$ (in Km).

Table 9. Result of the closed path around TH02.

\begin{tabular}{|c|c|c|c|c|c|c|c|}
\hline Points & DIST & LAR & LAV & $\Delta N$ & ALTI & $\mathrm{C} / \Delta N$ & ALT (comp) \\
\hline TH02 & & 1664 & & & 90.117 & & 90.117 \\
\hline 1 & 80 & 1462 & 1701 & -0.037 & 90.08 & 0.00012731 & 90.080 \\
\hline 2 & 100 & 1394 & 1396 & 0.066 & 90.146 & 0.00022709 & 90.146 \\
\hline 3 & 110 & 1323 & 1300 & 0.094 & 90.24 & 0.00032343 & 90.240 \\
\hline 4 & 130 & 1526 & 1525 & -0.202 & 90.038 & 0.00069503 & 90.039 \\
\hline 5 & 110 & 1132 & 1186 & 0.34 & 90.378 & 0.00116985 & 90.379 \\
\hline 6 & 120 & 818 & 872 & 0.26 & 90.638 & 0.00089459 & 90.639 \\
\hline K1 & 120 & 1182 & 1214 & -0.396 & 90.242 & 0.00136253 & 90.243 \\
\hline 7 & 120 & 2123 & 2093 & -0.911 & 89.331 & 0.0031345 & 89.334 \\
\hline 8 & 120 & 1605 & 1498 & 0.625 & 89.956 & 0.00215045 & 89.958 \\
\hline 9 & 120 & 1704 & 1662 & -0.057 & 89.899 & 0.00019612 & 89.899 \\
\hline 10 & 100 & 1692 & 1693 & 0.011 & 89.91 & $3.78 \mathrm{E}-05$ & 89.910 \\
\hline 11 & 100 & 1676 & 1693 & -0.001 & 89.909 & $3.4407 \mathrm{E}-06$ & 89.909 \\
\hline 12 & 100 & 1618 & 1617 & 0.059 & 89.968 & 0.000203 & 89.968 \\
\hline TH02 & 100 & & 1480 & 0.138 & 90.106 & 0.00047482 & 90.117 \\
\hline
\end{tabular}

Table 10. Result of the closed path around K1.

\begin{tabular}{cccccccc}
\hline Points & Distance & LAR $(\mathrm{mm})$ & LAV $(\mathrm{mm})$ & Dénivelée $(\mathrm{m})$ & ALT $(\mathrm{m})$ & Comp $(\mathrm{m})$ & ALT (comp) \\
\hline $\mathrm{K} 1$ & & 2011 & & & 90.243 & & 90.243 \\
1 & 110 & 1253 & 1252 & 0.759 & 91.002 & 0.001854 & 91.004 \\
$\mathrm{~K} 2$ & 160 & 1238 & 1207 & 0.046 & 91.048 & 0.000112 & 91.050 \\
3 & 100 & 1370 & 1414 & -0.176 & 90.872 & 0.00043 & 90.874 \\
4 & 130 & 569 & 585 & 0.785 & 91.657 & 0.001917 & 91.661 \\
5 & 130 & 1748 & 1728 & -1.159 & 90.498 & 0.00283 & 90.505 \\
$\mathrm{~K} 3$ & 120 & 1595 & 1588 & 0.16 & 90.658 & 0.000391 & 90.666 \\
6 & 100 & 1565 & 1560 & 0.035 & 90.693 & 0.0000855 & 90.701 \\
7 & 100 & 1187 & 1157 & 0.408 & 91.101 & 0.000996 & 91.110 \\
$\mathrm{~K} 4$ & 130 & 2231 & 2293 & -1.106 & 89.995 & 0.002701 & 90.006 \\
8 & 130 & 1140 & 1146 & 1.085 & 91.08 & 0.00265 & 91.094 \\
\hline
\end{tabular}




\begin{tabular}{cccccccc}
\multicolumn{1}{l}{ Continued } & \multicolumn{7}{c}{} \\
\hline 9 & 100 & 1207 & 1240 & -0.1 & 90.98 & 0.000244 & 90.994 \\
10 & 100 & 1528 & 1536 & -0.329 & 90.651 & 0.000803 & 90.666 \\
11 & 120 & 1411 & 1422 & 0.106 & 90.757 & 0.000259 & 90.772 \\
12 & 130 & 1360 & 1381 & 0.03 & 90.787 & 0.0000733 & 90.802 \\
13 & 130 & 1793 & 1779 & -0.419 & 90.368 & 0.001023 & 90.384 \\
14 & 100 & 2190 & 2142 & -0.349 & 90.019 & 0.000852 & 90.036 \\
15 & 160 & 1767 & 1747 & 0.443 & 90.462 & 0.001075 & 90.480 \\
K1 & 110 & & 2005 & -0.238 & 90.224 & 0.000703 & 90.243 \\
\hline
\end{tabular}

Table 11. Altitudes from leveling.

\begin{tabular}{cc}
\hline Points & Altitudes \\
\hline K1 & 90.243 \\
K2 & 91.050 \\
K3 & 90.666 \\
K4 & 90.006 \\
\hline
\end{tabular}

Table 12. Ripples of the K-point.

\begin{tabular}{cccc}
\hline Points & $\boldsymbol{h}($ RTK in $\mathbf{m})$ & Altitude $(\mathrm{GL}$ in $\mathrm{m})$ & $\boldsymbol{N}(\mathrm{m})$ \\
\hline K1 & 120.757 & 90.243 & 30.514 \\
K2 & 121.555 & 91.048 & 30.507 \\
K3 & 121.163 & 90.658 & 30.505 \\
K4 & 120.519 & 89.995 & 30.524 \\
\hline
\end{tabular}

It is noted that when the deviation in longitude and latitude is of the order of a millimeter, then the ripple variation is below a meter.

It is also noted that, for three points, when the deviation of longitudes is constant and the deviation of latitudes varies, the variation of the ripples is metric. This result therefore shows that the ripple varies with latitude.

Moreover, for three points, the latitude differences between these three points are close and the longitude differences vary. So, the variations of the ripple depend on the variations of the longitude.

Moreover, the ripple is a variable that depends on the variations of longitude and latitude.

\subsubsection{Altitude and Ripple}

Table 14 summarises the heights from EGM08 and their difference and the undulation at each point considered.

The mean square error (emq) is: $\sigma= \pm 0.041 \mathrm{~m}$. The value found verifies well the accuracy of EGM08 which is of the order of $5 \mathrm{~cm}$ in Senegal [1].

It is summarised in Table 14 that the difference vary between $-36 \mathrm{~mm}$ and $-45 \mathrm{~mm}$. 
Table 13. Variation of undulation with latitude and longitude.

\begin{tabular}{ccccccc}
\hline Points & Longitude $\left(^{\circ}\right)$ & Latitude $\left(^{\circ}\right)$ & $\Delta \lambda$ & $\Delta \phi$ & $N$ & $\Delta N$ \\
\hline K1 & -16.94580364 & 14.774593 & & & 30.514 & \\
& & & 0.00078232 & 0.00191619 & & -0.007 \\
K2 & -16.94658596 & 14.77267681 & & & 30.507 & \\
& & & 0.00402867 & 0.00070723 & & -0.009 \\
K3 & -16.94983231 & 14.77388577 & & & 30.505 & \\
& & & 0.0042569 & 0.00202804 & & -0.010 \\
K4 & -16.95006054 & 14.77662104 & & & 30.524 & \\
\hline
\end{tabular}

Table 14. Difference between elevation and undulation.

\begin{tabular}{ccccc}
\hline Points & Altitude (NG) & Altitude & Différence & Ondulation \\
\hline K1 & 90.243 & 90.286 & -0.043 & 30.514 \\
K2 & 91.048 & 91.084 & -0.036 & 30.507 \\
K3 & 90.658 & 90.697 & -0.039 & 30.505 \\
K4 & 89.995 & 90.04 & -0.045 & 30.524 \\
\hline
\end{tabular}

This means that for studies (e.g., pre-project) or leveling works that have to be carried out with a tolerance of a few centimeters, an accurate global geoid model such as the EGM2008 could be used. However, the best solution is still to use a local geoid model, as is the case in many developed countries.

\section{Conclusions}

From these results, the contribution of GNSS in terms of altimeter linking is highlighted. However, it is important to keep in mind that despite the approximation of the results, geometric leveling remains the most accurate operation to altimetrically link a point.

This study has helped to understand and establish the limitations of GNSS and conventional surveying.

It also allowed answering several questions raised between GNSS and conventional topography.

The results of this study have shown the contribution of GNSS in terms of time saving and accuracy and under certain constraints.

It should be noted that these contributions currently concern all the classical domains except leveling when the environmental conditions allow the use of GNSS. But, nevertheless, it should just be known that with some treatments reported in our studies, GNSS can come close to direct leveling when associated with a global geoid model such as EGM2008. Leveling remains the field of topography where GNSS does not yet give very satisfactory results by simple use in countries such as Senegal where we note an absence of a precise local geoid model that could be derived from gravimetric, leveling and GNSS measurement campaigns. 


\section{Acknowledgements}

We thank all those who have contributed to the production of this document.

\section{Conflicts of Interest}

We declare no conflict of interest for this document.

\section{References}

[1] Ba, A., Fall, A., Thioune, P.B.D. and Diaw, El H.B. (2019) The Development and Validation of an EGM2008 Geoid Model for Senegal. International Journal of Advanced Research, 7, 750-755. https://doi.org/10.21474/IJAR01/9724

[2] Graber, F. (2006) Leveling a Measurement for Acting 1800. Mesurer le Ciel et la Terre, 29-54. https://doi.org/10.4000/histoiremesure.1745

[3] Duquenne, F., L'ecu, F. and Gazeau, J. (2017) Geoïde: Mythe ou réalité? REVUE $\mathrm{XYZ}-1^{\mathrm{ER}}$ trimestre, 39-48.

[4] Lionel, V., Aronica, C., Calmettes, S., Demange, N., Demange, M., Gerard, J., Lavielle, M.-L., Saury, C. and Venturi, M. (2017) Chimie PC/PC $\mathrm{P}^{\star}-2 \mathrm{e}$ édition actualisée. Edition Ellipse, Paris, 720 p.

[5] Núñez, M.A., Martin, A., Gili, J.A. and Anquela, A.B. (2008) High-Precision Geoid Determination in Small Areas: A Case Study in Doñana National Park (Spain). Studia Geophysica et Geodaetica, 52, 361-380. https://doi.org/10.1007/s11200-008-0026-y

[6] Lee, S.-B. and Kim, C.-Y. (2011) Development of Regional Gravimetric Geoid Model and Comparison with EGM2008 Gravity-Field Model over Korea. Scientific Research and Essays, 7, 387-397.

[7] Barthelmes, F. (2013) Definition of Functionals of the Geopotential and Their Calculation from Spherical Harmonic Models. Scientific Technical Report STR09/02. http://icgem.gfz-potsdam.de/str-0902-revised.pdf

[8] Nocquet, J.-M., Duquenne, H., Boucher, C., Harmel, A. and Willis, P. (2000) Conversion altimétrique RGF93-IGN69.

http://bazar.perso.free.fr/Files/Other/DOCUMENTATION/topo/conv alti\%20IGN 93-RGF69.pdf

[9] Rey, J.-M. (1997) Technique GPS en mode cinématique. Mensuration, Photogrammétrie, Génie Rural, Vol. 95. http://doi.org/10.5169/seals-235359

[10] Santerre, R. and Forgues, I. (1993) Méthode statique rapide GPS: Principes et résultat. http://gps-rs.scg.ulaval.ca/pdf/Geomatique 20(4).pdf 